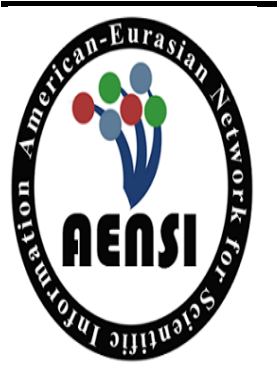

AUSTRALIAN JOURNAL OF BASIC AND APPLIED SCIENCES

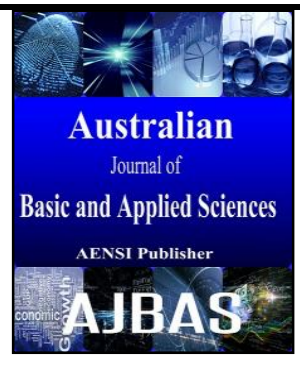

\title{
Experimental Infection and Evaluation of Airborne Transmission And Nose-To-Nose Contact of Bovine Viral Diarrhea Virus Among Weaned Piglets
}

${ }^{1}$ Anne Caroline Ramos dos Santos, ${ }^{1}$ Karla Alvarenga Nascimento, ${ }^{1}$ Marina Lopes Mechler, ${ }^{1}$ Henrique Meiroz dos Santos Almeida, ${ }^{1}$ Igor Renan Honorato Gatto, ${ }^{1}$ Luiz Gabriel Ferreira Carnielli, ${ }^{1}$ Andressa de Souza Pollo, ${ }^{2}$ Luís Guilherme de Oliveira

${ }^{I}$ College of Agricultural and Veterinary Sciences (FCAV), São Paulo State University (Unesp). Via de Acesso Prof. Paulo Donato Castellane s/n, Jaboticabal, SP 14884-900, Brazil.

${ }^{2}$ Department of Veterinary Clinic and Surgery, College of Agricultural and Veterinary Sciences (FCAV), São Paulo State University (Unesp). Via de Acesso Prof. Paulo Donato Castellane s/n, Jaboticabal, SP 14884-900, Brazil.

\section{Address For Correspondence:}

Luís Guilherme de Oliveira, Department of Veterinary Clinic and Surgery, College of Agricultural and Veterinary Sciences (FCAV), São Paulo State University (Unesp). Via de Acesso Prof. Paulo Donato Castellane s/n, Jaboticabal, SP 14884-900, Brazil.

Email: luis.guilherme@fcav.unesp.br

\section{ART ICLE INFO}

\section{Article history:}

Received 12 October 2017

Accepted 22 December 2017

Available online 31 December 2017

Keywords:

$B V D V$, isolators, swine, $R T-P C R$, virus neutralization,

\begin{abstract}
A B S T R A C T
BACKGROUND: Swine under natural conditions may become infected with Bovine Viral Diarrhea Virus (BVDV). It is known that BVDV transmission to pigs requires direct or indirect contact with secretions of infected animals. However, the transmission routes among pigs still remain unknown. OBJECTIVE: The objective of this study was to verify, under experimental conditions, whether piglets infected with BVDV can shed the virus and transmit it by air and nose-to-nose contact. For that, two experiments performed with two repetitions were carried out, using six animals in each one. All of the selected piglets were free of BVDV infection by virus neutralization and formed three random groups: Control, Sentinel and Infected, each group composed by two animals. Isolation chambers were used to eliminate other transmission routes, which were specially designed to establish contact between the animals only by the route proposed. The animals were housed in the isolators for 25 days, during which they underwent clinical evaluations and daily samples of nasal swabs for RT-PCR, and serum samples were collected every four days for virus neutralization test. At the end, the animals were euthanized and organ fragments were collected and submitted to histopathology and RT-PCR. RESULTS: Piglets from the infected group, in airborne experiment, presented seroconversion and the presence of viral RNA in tissues; however in the nose-to-nose experiment neutralizing antibodies and RNA viral were not detected in any of the samples. Viral excretion and clinical signs were present in both experiments, confirming the success of the infection. However, in the control and sentinel groups, there was no seroconversion or detection of virus genetic material in the samples. CONCLUSION: Thus, it was concluded that BVDV-1 is capable of causing infection in pigs, being present in secretions and developing clinical signs. Nevertheless, there was no airborne transmission during the evaluated period, inferring limited transmission capacity among pigs.
\end{abstract}

\section{INTRODUCTION}

The genus Pestivirus cause important diseases in production animals, as the main ones are Bovine Viral Diarrhea (BVD), Border Disease (BD) in sheep and goats, and Classical Swine Fever (CSF) (Schweizer and Peterhans, 2014). In healthy adult animals, the clinical sign of the disease may be subclinical, and in

Open Access Journal

Published BY AENSI Publication

(C) 2017 AENSI Publisher All rights reserved

This work is licensed under the Creative Commons Attribution International License (CC BY). http://creativecommons.org/licenses/by/4.0/

\section{Open Access}

To Cite This Article: Anne Caroline Ramos dos Santos, Karla Alvarenga Nascimento, Marina Lopes Mechler, Henrique Meiroz dos Santos Almeida, Igor Renan Honorato Gatto, Luiz Gabriel Ferreira Carnielli, Andressa de Souza Pollo, Luís Guilherme de Oliveira, Experimental Infection and Evaluation of Airborne Transmission And Nose-To-Nose Contact of Bovine Viral Diarrhea Virus Among Weaned Piglets. Aust. J. Basic \& Appl. Sci., 11(15): 12-19, 2017 
immunocompetent animals and pregnant females, the BVDV infection can cause reproductive disorders (Fino et al., 2012).

The virus may lead temporary infertility, embryonic resorption, abortions, stillbirths, malformations and generation of persistently infected calves (Moennig and Becher, 2015). Under severe infection it is possible to observe thrombocytopenia, high fever, hemorrhage and high mortality (Schweizer and Peterhans, 2014). Seroconversion by cattle occurs between 14 and 28 days after infection, and antibodies can be detected up to 3 years after the occurrence of the clinical condition (Chase, 2013). Although the BVDV is related to cattle, this pathogen can affect different animal species such as sheep, goats, swine, bison, alpacas, llamas and white-tailed deer (Walz et al., 2010).

In most cases, these animals do not show clinical signs, allowing a silent viral dissemination among the herd (Walz et al., 2004). Ruminant pestivirus show relatively limited infectivity in swine, however, in immunosuppressed animals, the infection can affect the respiratory, digestive, reproductive and circulatory systems (Silva, 2011; Tao et al., 2013). Difficulties in the serological differentiation between BVDV and CSFV, due to cross reactions, can lead to diagnostic complications, and consequent obstacles in epidemiological surveillance for CSF (Frías Lepoureau et al., 2003).

Epidemiological studies place cattle as the main host of BVDV, being the most important source of infection for pigs and other wild ruminants (Ridpath, 2010). Direct contact with livestock on the same property is considered to be the primary source of BVDV infections in pigs (Liess and Moennig, 1990). Transmission may also occur due to the use of milk and other derivatives from infected cattle in pig feeding (Terpstra and Wensvoort, 1997).

BVDV transmission between cattle and pigs requires direct contact between these animals. Nonetheless, transmission of the virus among swine has not yet been clarified and requires further information (Leforban $e t$ al., 1992; Tao et al., 2013). Given the possibility of cross-infection of BVDV between cattle and pigs, it is extremely important to know the virus transmission routes among swine, since being hosts of the virus, can cause uncontrolled dissemination of the pathogen in the herd, leading to productive and economic losses, besides hindering serological monitoring of classical swine fever. Thus, this work aims to evaluate the possibility of excretion of BVDV by experimentally infected piglets and viral airborne transmission.

\section{MATERIAL AND METHODS}

\section{Animal selection:}

Two experimental inoculation of BVDV-1 were carried out, one for assessing airborne transmission and other for assessing the nose-to-nose one, followed by one repetition each. For that, were selected 24 weaned piglets from the same litter of commercial breeds, with approximately 21 days old, presenting good body score, from a commercial farm with biosecurity standards.

The selection was done after blood collection from the piglets and the sow to confirm the absence of antibodies against BVDV by Virus neutralization (VN), as recommended by the "Manual of Diagnostic Tests and Vaccines of Terrestrial Animals" (OIE, 2012).

The animals were identified with earrings, fed with autoclaved feed and water. The room temperature at which the animals were housed remained constant at $25^{\circ} \mathrm{C}$.

\section{Experimental design:}

These experiments were carried out in accordance with the ethical principles adopted by the National Council for the Control of Animal Experimentation (CONCEA) and approved by the Committee on Ethics in the Use of Animals (CEUA) (reference number 07998/14, 08/05/2014).

For the experimental inoculation with BVDV-1, the piglets remained in observation for seven days in isolated pens. During this period, samples of blood and nasal swab were collected and analyzed using virus neutralization (VN) and RT-PCR, respectively (Weinstock et al., 2001), proving that the animals were seronegative and free of viremia.

Due to the limited capacity of each cabinet, six piglets were used per experiment, randomly assigned into three equal groups $(n=2)$ : control, sentinel and infected, to evaluate the excretion and possible transmission of BVDV-1, as shown in Table 1.

The infected group was inoculated with BVDV-1, Singer strain. Viral inoculum was produced through viral replication in Madine Darby Bovine Kidney (MDBK) cells and later stored in Eagle-Minimal Essential Medium (E-MEM) medium.

Two inoculums were prepared for this study, one for the airborne experiment and other for the nose-to-nose one.The average titer of the inoculum was $10^{5,58}$. Determination of titer was performed according to the method proposed by Reed and Muench (1938).

The BVDV inoculation in the infected group followed the method recommended by Cabezón et al. (2010). Scarification on the snout of the piglets was performed to enable the inoculum to be contacted with the bloodstream, 
and the inoculation in the infected group was done intranasally, by instillation of $2.5 \mathrm{~mL}$ of viral suspension in each nostril, and by oral route with syringe, being administered the volume of $5.0 \mathrm{~mL}$. Control and sentinel animals received $10 \mathrm{~mL}$ of placebo containing E-MEM medium, which was given by the same routes.

In this study, each experiment was conducted for 25 days, as samples of nasal swabs were collected daily and blood collected every 7 days by jugular venipuncture.

At the time of each collection, general clinical evaluation of the animals was carried out, with rectal temperature measurement and evaluation of clinical signs. On the $25^{\text {th }}$ day of the experiment, the animals were euthanized and necropsied. Samples of spleen, ileum, mesenteric lymph node, mediastinal lymph node, inguinal lymph node, lung, kidney, liver and tonsils were collected.

Table 1: Distribution of animals per group in the experiments to assess BVDV transmission route airborne and nose to nose, in experimentally infected piglets. Jaboticabal, SP, 2015-2016.

\begin{tabular}{|c|c|c|c|c|c|}
\hline Transmission route & ID & $\begin{array}{c}\text { N of infected } \\
\text { animals }\end{array}$ & N of sentinel & N of control & Total per repetition \\
\hline Airborne & AI & 2 & 2 & 2 & 6 \\
\hline Airborne & AII & 2 & 2 & 2 & 6 \\
\hline Nose to Nose I & NN I & 2 & 2 & 2 & 6 \\
\hline Nose to Nose I & NN I & 2 & 2 & 6 \\
\hline
\end{tabular}

*ID: Identification of experiments, $\mathrm{N}$ : number of animals.

\section{Isolators:}

For the assessment of the transmission route, stainless steel isolation cabinets $(0.80 \mathrm{~m} \times 0.80 \mathrm{~m} \times 1.30 \mathrm{~m})$ were used, completely closed and specifically designed for epidemiological studies, according to the design developed from a prototype recommended by Torremorell et al. (1997) and used by Oliveira et al., (2006; 2007; 2010) (Figures 1 and 2), belonging to Swine Research Laboratory of the Faculty of Agricultural and Veterinary Science - Unesp/Jaboticabal.

The isolation cabinets allow feed and water input without opening the system, as well as the material for blood and swab collection which are passed through a transition chamber.

For the accomplishment of each experiment, the isolators were placed in the correct conformation, so that there was no outside interference. In relation to the assembly of the isolators of the experiment to verify the aerogenic route, the insulators were mounted so that the air passed through a single direction: control, sentinel and infected, respectively. The nose-to-nose transmission, the isolators were interconnected with an orifice, in a way that infected animals and sentinels could establish nose contact, being the only form of contact between the animals.

Ventilation of the system was performed by continuous, non-returning air flow through sterile ducts connecting the cabinets to the ventilating unit and the exhaust fan. Both units, the exhauster (Exaust flow 500, Filtracom Ltda, Campinas, SP) and the fan (Steril flow 500, Filtracom Ltda) are equipped with HEPA pre-filters and absolute filters, with $99.97 \%$ efficiency for particles bigger than $0.3 \mu \mathrm{m}$.

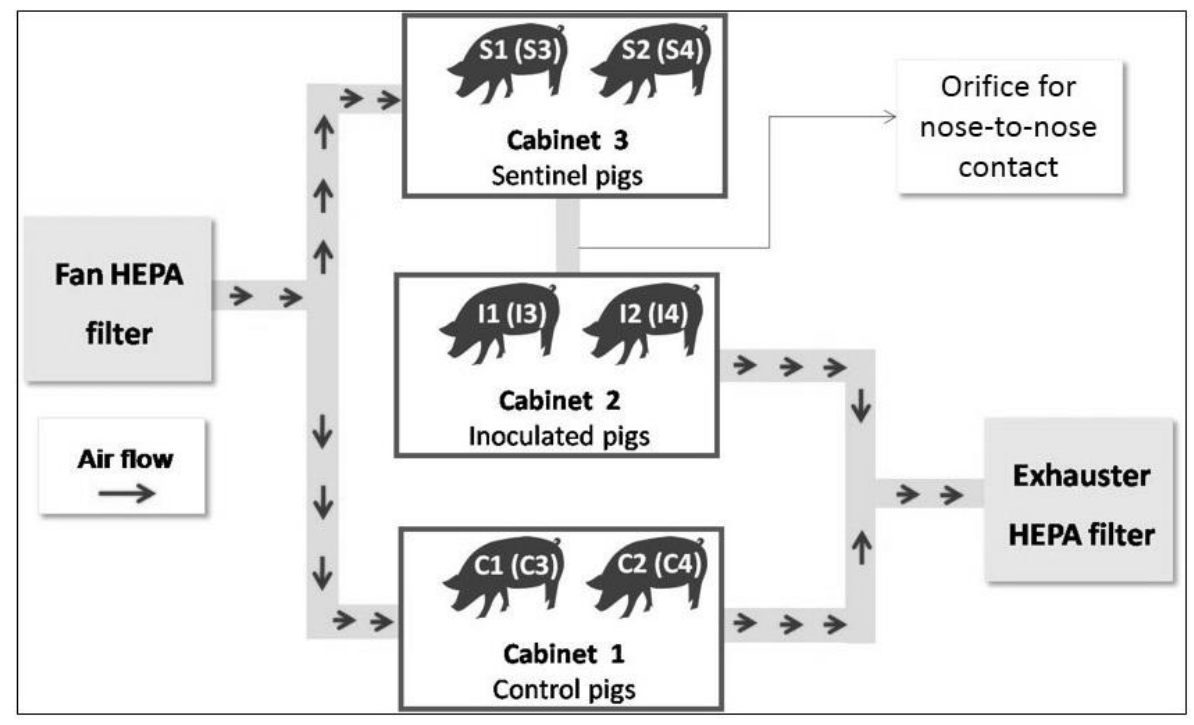

Fig. 1: Schematic representation of the isolator assembly for the study of nose-to-nose transmission route. Jaboticabal, SP, 2016. 


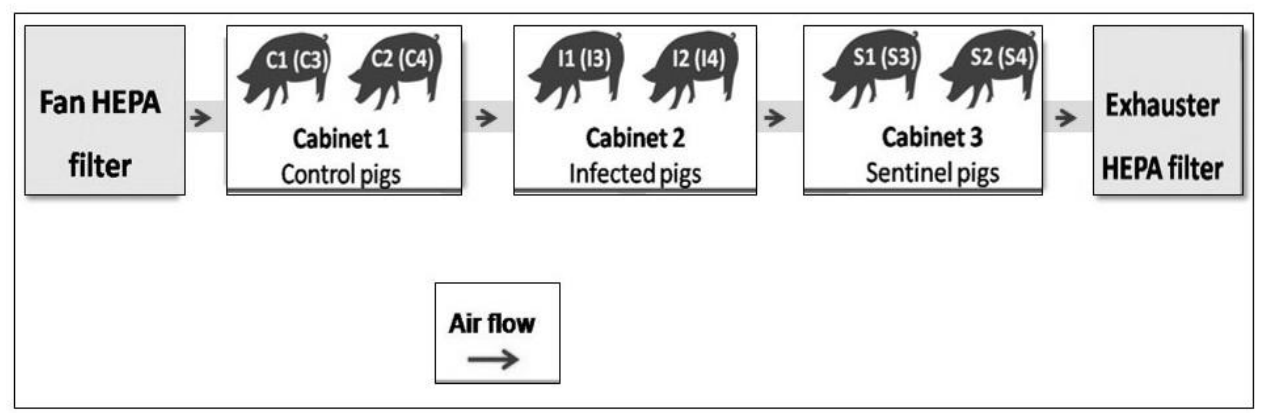

Fig. 2: Schematic representation of the isolator assembly for the study of airborne transmission route. Jaboticabal, SP, 2016.

\section{Virus neutralization $(V N)$ :}

Serum samples were submitted to Virus neutralization test. The sera to be tested were collected in duplicates and subjected to successive dilutions starting at 1:10 up to 1:5120, considering positives the samples showing total neutralization of the $100 \mathrm{TCID}_{50}$ at a dilution above 1:10, as recommended by the "Manual of Diagnostic Tests and Vaccines of Terrestrial Animals" (OIE, 2012). For the test were used bovine kidney epithelial cell lineage "Madine-Darby Bovine Kidney" (MDBK,) and as standard virus, the cytopathic (CP) BVDV-1 (Singer strain). The antibody titer considered for positive samples was equivalent to the reciprocal of the highest dilution in which total neutralization of the $100 \mathrm{TCID}_{50}$ occurred, evidenced by the absence of cytopathic effect in the cell culture.

\section{Histopathology and Immunohistochemistry (IHC):}

Fragments of spleen, ileum, mesenteric lymph node, mediastinal lymph node, inguinal lymph node, lung, kidney, liver and tonsils from both experiments were fixed in $10 \%$ buffered formalin and routinely processed for paraffin inclusion and hematoxylin-eosin staining (HE).

The IHC technique was performed in all histological sections, using the technique as described by Haines et al. (1992). Slides were silanized and subjected to antigen retrieval with protease XIV for 15 minutes. Subsequently, endogenous peroxidase blockade was performed with $4 \% \quad \mathrm{H}_{2} \mathrm{O}_{2}$ solution, non-specific binding block with commercial Kit (DAKO LSAB + System - HRP Biotinylated Link Universal Streptavidin - HRP) and incubation with monoclonal antibody D89 (VMRD, Inc., Pullman, USA) diluted in bovine serum albumin (BSA) at a concentration of 1:150 applied for 14 to 16 hours (overnight) at $4^{\circ} \mathrm{C}$, in a humified chamber.

The following day, incubation was carried out with the secondary antibody, diaminobenzidine revelation (DAKO- Liquid DAB + Substrate, Chromogen System DAB + Chromogen DAB + Substrate Buffer) and counterstaining with HE. As a positive control BVDV-positive bovine epithelium fragment was used in all the tests performed.

\section{RT-PCR:}

Samples of nasal swab and fragments of spleen, ileum, mesenteric lymph node, mediastinal lymph node, inguinal lymph node, lung, kidney, liver and tonsil from both experiments were evaluated for the presence of BVDV genetic material by RT-PCR. Collected swabs were stored in sterile, RNA-free microtubes containing $0.3 \mathrm{ml}$ of EMEM (Eagle's Minimal Essential Medium) supplemented with antibiotics (streptomycin 1\%). As negative control, a sample containing only PCR reagents was used.

RNA from the samples was extracted using Trizol (Sigma) and converted into cDNA by using the kit HighCapacity cDNA Reverse Transcription (Applied Biosystems), According to the manufacturer's instructions. A conventional PCR for virus identification was performed using sense primers 103 (5'- TAG CCA TGC CCT TAG TAG GAC - 3') and 392 antisense (5'- ACT CCA TGT GCC ATG TAC AGC - 3') which amplifies a product of 290 bp (Weinstock et al., 2001).

The PCR product obtained for the genes identification was used for the reamplification reaction using the same set of primers, aiming at increasing the amount of amplified product. It was conducted employing primers that bind to the highly conserved region of the BVDV genome located in 5 'end of the NADL strain, which shares maximum homology with the BVDV genotypes type 1 and 2.

For the first PCR reaction, buffer $1 \mathrm{X}$ was used (20 mM Tris- $\mathrm{HCl} \mathrm{pH} 8,4 ; 50 \mathrm{mM} \mathrm{KCl}), 2 \mathrm{mM} \mathrm{MgCl} 2,0,2 \mathrm{mM}$ dNTPs, $1,0 \mathrm{U}$ Taq DNA polimerase, 5 pmol of each primer, $5 \mu \mathrm{L}$ of cDNA and water for $20 \mu \mathrm{L}$. Amplification of the fragments occurred in a Nexus thermocycler (Eppendorf) programmed to cycle at $95^{\circ} \mathrm{C}$ for 4 minutes, 35 cycles at $94^{\circ} \mathrm{C}$ for 40 seconds, $60^{\circ} \mathrm{C}$ for 40 seconds, and $72^{\circ} \mathrm{C}$ for 40 seconds, followed by a final cycle of $72^{\circ} \mathrm{C}$ for seven minutes. 
The product of the first PCR was used instead of the cDNA to perform the second PCR, which occurred under the same conditions of PCR 1, with the same pair of primers. In all reactions positive controls were used, containing BVDV genetic material, and negative controls with absence of genetic material. The amplification products were submitted to $1 \%(\mathrm{w} / \mathrm{v})$ agarose gel electrophoresis containing ethidium bromide $(0.5 \mathrm{mg} / \mathrm{mL})$, and visualized by Geldoc XR photodocumentation equipment (BioRad, USA).

\section{Results:}

In both experiments, the induction of experimental infection was successful, since all inoculated animals were able to respond immunologically to the viral antigen.

In the airborne route at the $25^{\text {th }} \mathrm{dpi}$ of the first experiment, the animals of the infected group (AI -I1 and I2) presented antibody titers against BVDV-1 of 40 and 160, respectively (Table 2). Viral RNA was observed in nasal swabs at $17^{\text {th }}$ dpi of animal AI-I1, proving nasal excretion, although the detection of viral genetic material was not observed in the posterior samples. The same animal showed positivity for the viral antigen in liver, spleen and kidney samples. No animal presented relevant macroscopic and histological findings. Clinically, the infected animals presented diarrhea at $4^{\text {th }}$ dpi, persisting for five days. Statistically, there was no significant difference of mean body temperatures among control, infected and sentinel animals.

In the following repetition, both inoculated piglets (AII- I3 and I4) showed antibodies against BVDV-1 with titers of 10 and 20 , respectively, at $25^{\text {th }}$ dpi. However, viral RNA was not detected either in the swab samples or in their organs. Regarding the clinical signs, the infected group showed clear weight loss and rough hair when compared to the control and sentinel groups after 15 days of inoculation. No animal presented relevant macroscopic and histological findings. Statistically, there was no significant difference of mean body temperatures among the groups.

In the nose-to-nose experiment, the results (Table 3) showed that in the first repetition, the both piglets of the infected group seroconverted at 25th day post infection (dpi), with antibody titer of 80 . Despite antibodies were detected only in the last day of the experiment, the detection of viral genetic material through RT-PCR in nasal swabs occurred in one of the infected animals (NNI-I2) on the 17th and 21st dpi.

Regarding the second repetition, only one infected piglets seroconverted at 25th dpi with an antibody titer of 20 (NNII-I3). However, viral genetic material was detected in both infected animals, animal I3 was positive on 10,11, 14, 15, 16 and 18 dpi. Animal NNII-I4, on the other hand, had nasal swabs samples positive at 18, 19, 22, 13 dpi. The infected animals presented clinical signs such as diarrhea and rough fur coat from 15 dpi and on, matching the detection of viral shedding in the swabs.

At necropsy, no gross lesions were observed in any of the animals of the experiment. At microscopic level no lesions were detected when compared to the control group, suggesting that the BVDV was not capable of induce lesions. In addition, no remarkable staining was observed in the IHC slides.

In both experiments, control and sentinel animals did not show clinical signs, seroconversion, and virus genetic material was not detected in swabs and tissues. Table 2 summarizes the results of RT-PCR, virus neutralization and clinical signs.

Table 2: Results of the laboratory tests of RT-PCR and virus neutralization, and clinical signs of weaned piglets assessed in two experiments to evaluate the airborne transmission of BVDV-1

\begin{tabular}{|c|c|c|c|c|c|}
\hline & & RT-PCR swabs & RT-PCR organs & VN $(25 \text { dpi })^{*}$ & Clinical signs \\
\hline \multirow{6}{*}{ AI } & Infected (I1) & $17^{\text {th }}$ dpi & $\begin{array}{l}\text { Liver, kidney and } \\
\text { spleen }\end{array}$ & 40 & diarrhea \\
\hline & Infected (I2) & - & - & 160 & diarrhea \\
\hline & Sentinel (S1) & - & - & - & No \\
\hline & Sentinel (S2) & - & - & - & No \\
\hline & Control (C1) & - & - & - & No \\
\hline & Control (C2) & - & - & - & No \\
\hline \multirow{6}{*}{ AII } & Infected (I3) & - & - & 10 & weight loss and rough hair \\
\hline & Infected (I4) & - & - & 20 & weight loss and rough hair \\
\hline & Sentinel (S3) & - & - & - & No \\
\hline & Sentinel (S4) & - & - & - & No \\
\hline & Control (C3) & - & - & - & No \\
\hline & Control (C4) & - & - & - & No \\
\hline
\end{tabular}

Table 3: Results obtained by RT-PCR and Virus neutralization for molecular and serological detection of BVDV and antibodies, detailing the moment of shedding and seroconversion. Jaboticabal, SP, 2015-2016.

\begin{tabular}{|c|c|c|c|c|}
\hline \multicolumn{2}{|c|}{ Experiment } & $\begin{array}{c}\text { Viral shedding diagnosed by PCR } \\
(\mathrm{dpi})\end{array}$ & $\begin{array}{c}\text { Antibodies titers } \\
\text { Moment of antibodies } \\
\text { detection (dpi) }\end{array}$ \\
\hline & Infected (I1) & - & 80 & $25^{\text {th }}$ \\
- & - & - \\
\hline NN-I & Infected (I2) & - & - & - \\
\hline & Sentinel (S1) & - & - & - \\
\hline
\end{tabular}




\begin{tabular}{|l|l|c|c|c|}
\hline & Control (C1) & - & - & - \\
\hline & Control (C2) & - & 20 & - \\
\hline & Infected (I3) & $10,11,14,15,16,18$ & - & - \\
& Infected (I4) & $18,19,22,23$ & - & - \\
\hline NN-II & Sentinel (S3) & - & - & - \\
\hline & Sentinel (S4) & - & - & - \\
\hline & Control (C3) & - & - & - \\
\hline
\end{tabular}

*NN-I: experiment nose to nose 1; NN-II: experiment nose to nose 2; dpi: days post-infection; PCR: Polimerase Chain Reaction

\section{Discussion:}

Several experimental infections with pestivirus have been performed on pigs, but there are few studies on experimental infections with BVDV and information on clinical signs. The data obtained in this work confirm the BVDV's ability to promote infection in pigs, causing clinical signs and leading the immune response to the antigen. Studies of experimental infection of pigs by BVDV report that the infection may be subclinical (Walz et al., 1999; 2004; Wieringa-Jelsma et al., 2006; Langohr et al., 2012), and at the same time may occur with viral dissemination in the organs of infected animals (Bachofen et al., 2014).

The humoral immune response to pestivirus in pigs was previously reported to be highly variable after the onset of infection. Authors reported levels of detectable BVDV antibodies five weeks after infection in sows, while others showed evidence of seroconversion within 3 weeks after inoculation of pigs with a BDV strain (Leforban et al., 1992; Walz et al., 2004). In the present study, seroconversion of all infected animals was observed at least two to three weeks after viral inoculation. Under field conditions, free of stress, the antibodies produced are able to attenuate the evolution of the infection and prevent the continuous excretion of the virus. On the other hand, in the nose-to-nose experiment, the viral shedding began at $10 \mathrm{dpi}$ and was observed until the end of the experiment; however, no consistent pattern was detected. This finding is different from for the ones in bovine hosts, which present a 48-72h post infection viral shedding (Moser, 2011).

The viral excretion detected in nasal swabs of the infected animal in airborne experiment (I1), possibly occurred due to the conditions of confinement to which the animals were submitted, taking into account the isolation model proposed in this study. The presence of viral RNA in the nasal swab may represent an active excretion of the agent by this route, as well as viral replication in the inoculated region.

Immunosuppression caused by viral infection (Chase, 2013) may have contributed to the evolution of the infection. The presence of BVDV in the nasal secretions and kidney of one of the inoculated animals by airborne route makes it possible for pigs to become sources of infection for other animals, especially if they are carriers of highly virulent BVDV strains. In the literature, the excretion of BVDV by a persistently infected boar was reported by Terpstra and Wensvoort (1997), who detected the virus in the oropharyngeal fluid, urine, and semen.

Similarly, Cabezón et al. (2010) found seroconversion and viral excretion in nasal swabs of animals infected with BDV, but the airborne transmission was not detected, even 28 days after excretion detection. An experimental inoculation study of BVDV in pigs showed that rates of virus transmission among pigs under field conditions are very low and, under experimental conditions, the possibility of transmission would be even more limited (Wieringa-Jelsma et al., 2006). In this study, the airborne transmission of the virus between the infected and the sentinel groups was not possible to demonstrate.

According to Penrith, Vosloo \& Mather (2011), the course of the infection depends on the virulence of the viral strain and the immune response of the pig. In immunocompetent bovines, neutralizing antibodies can be detected in the serum between two and three weeks post infection, which are believed to stop the virus from reaching the organs (Brownlie, 2002). It is important to note that the difficulty of detecting viral RNA in blood samples does not necessarily exclude the occurrence of viremia in the studied period, since BVDV viremia in pigs may be of a transient nature, occurring in short intervals. Likewise, the non-detection of viral genetic material in nasal swabs does not imply the absence of excretion, since a low excreted viral load may not be detected by the molecular technique used.

Although BVDV does not typify a significant threat to swine herds, the presence of the virus in the herd may culminate in cross-reactivity with CSFV, due to the antigenic similarity, negatively interfering with the surveillance programs of Classical Swine Fever and leading to diagnostic confusions of the disease (Loeffen et $a l ., 2009)$. In addition, this study confirms that BVDV has the capacity to remain in organs and physiological secretions of pigs. Thus, studies on the transmission of BVDV among this species should be encouraged, since pigs may be healthy carriers of more virulent field strains, serving as an important source of infection within the herd and leading to economic losses for producers.

\section{Conclusion:}

This experiment demonstrated the importance of the study of BVDV epidemiology in pigs. The experimental infection of piglets with BVDV-1 proved that the virus is capable of infecting pigs and causing clinical signs. Immune response, and the ability to lodge in organs such as kidneys, liver, and spleen, and to be 
present in nasal secretions were also confirmed through this study. However, the airborne and nose-to-nose transmission of the virus among piglets has not been proven within the evaluated period.

\section{Statements:}

This work demonstrated the importance of research on BVDV in pigs and search for more information on the epidemiology of the disease.

\section{AKNOWLEDGEMENTS}

This work was supported by FAPESP - São Paulo Research Foundation [grant number 2014/13590-3].

\section{REFERENCES}

Bachofen, C., D.M. Grant, K. Willoughby, R.N. Zadoks, M.P. Dagleish, G.C. Russell, 2014. Experimental infection of rabbits with bovine viral diarrhea virus by a natural route of exposure. Veterinary Research, $45 ; 34$. doi:10.1186/1297-9716-45-34.

Brownlie, J., 2002. Bovine virus diarrhea virus: pathogenesis and control. Proc. XXII World Buiatric Congress. Hannover, pp: 24-30.

Cabezón, O., R. Rosell, M. Sibila, S. Lavín, I. Marco, J. Segalés, 2010. Experimental infection of pigs with border disease virus isolated from Pyrenean chamois (Rupicapra pyrenaica). Journal of Veterinary Diagnostic Investigative, 22: 360-365. doi 10.1099/vir.0.034595-0.

Chase, C.C., 2013. The impact of BVDV infection on adaptive immunity. Biologicals, 41(1): 52-60. doi: 10.1016/j.biologicals.2012.09.009.

Fino, T.C.M., C.B. Melo, A.F. Ramos, R.C. Leite, 2012. Diarréia bovina a vírus (BVD) - uma breve revisão. Rev. Bras. Med, 34(2): 131-140.

Frías Lepoureau, M.T., M.I. Percedo Abreu, P. Naranjo Valdés, J.M. Sánchez-Vizcaíno, 2003. Reconociendo la peste porcina clásica, manual ilustrado. UP Producción Gráfica MINREX Press, Cuba.

Langohr, I.M., G.W. Stevenson, E.A. Nelson, S.D. Lenz, H. Wei, R.M. Pogranichniy, 2012. Experimental coinfection of pigs with bovine viral diarrhea virus 1 and porcine circovirus-2. Journal of Veterinary Diagnostic Investigative, 24: 51-64. doi: 10.1177/1040638711417142.

Leforban, Y., P. Vannier, R. Cariolet, 1992. Protection of piglets born from ruminant pestivirus experimentally infected sows and their contact, to the challenge with hog cholera virus. Annual Research Veterinary, 23: 73-82. Liess, B., V. Moennig, 1990. Ruminant Pestivirus Infection in Pigs. Revue Scientifique et Technique de L`Office International des Epizooties, França, 1(9): 151-161.

Loeffen, W.L.A., A. Van Beuningen, S. Quak, A.R.W. Elbers, 2009. Seroprevalence and risk factors for the presence of ruminant pestiviruses in the Dutch swine population. Veterinary Microbiology, (136): 240-245.

Moennig, V. and P. Becher, 2015. Pestivirus control programs: how far have we come and where are we going? Animal Health Research Reviews, 16(1): 83-87.

Moser, A.P., 2011. Reação Cruzada por Diarreia Viral Bovina Versus Peste Suína Clássica: Estudo de Caso. Universidade Federal do Paraná. Curitiba, pp: 67.

Oie., 2013. World Organization for Animal Health. Manual of Diagnostic Tests And Vaccines For Terrestrial Animals 2012. http://Www.Oie.Int/Fileadmin/Home/Eng/Health_Standards/Tahm/2.04.08_Bvd.Pdf Accessed 09 March.

Penrith, M.L., W. Vosloo, C. Mather, 2011. Classical swine fever (hog cholera): review of aspects relevant to control. Transbourdinary Emergency Disease, 58(3): 187-196. doi: 10.1111/j.1865-1682.2011.01205.x.

Reed, L.J. and H. Muench, 1938. A simple method of estimating 50 per cent end point. American Journal of Hygiene, 27: 493-497.

Ridpath, J.F., 2010. Bovine viral diarrhea virus: global status. Veterinary Clinics of North America: Food Animal Practice, 26(1): 105-121. doi:10.1016/j.cvfa.2009.10.007.

Schweizer, M. and E. Peterhans, 2014. Pestiviruses. Annual Review of Animal Bioscience, 2: 141-163. doi: 10.1146/annurev-animal-022513-114209.

Silva, M.V.M., J.L. Nogueira, V.P. Junior, R.A. Fernandes, 2011. Diarreia viral bovina: patogenia e diagnósticos - revisão de literatura. Revista Científica Eletrônica de Medicina Veterinária, 9: 16.

Tao, J., J. Liao, Y. Wang, X. Zhang, J. Wang, G. Zhu, 2013. Bovine viral diarrhea virus (BVDV) infections in pigs. Veterinary Microbiology, 165: 185-189. doi: 10.1016/j.vetmic.2013.03.010.

Terpstra, C. and G. Wensvoort, 1997. A congenital infections of bovine viral diarrhea virus in pigs: clinical, virological, and immunological observations. Veterinary Quaterly, 19: 97-101. doi: 10.1080/01652176.1997.9694750. 
Torremorell, M., C. Pijoan, K. Janni, R. Walker, H.S. Joo, 1997. Airborne transmission of Actinobacillus pleuropneumoniae and porcine reproductive and respiratory syndrome virus in nursery pigs. American Journal of Veterinary Research, 58: 828-832.

Walz, P.H., J.C. Baker, T.P. Mullaney, J.B. Kaneene, R.K. Maes, 1999. Comparison of type I and type II bovine viral diarrhea virus infection in swine. Canadian Journal of Veterinary Research, 63: 119-123.

Walz, P.H., J.C. Baker, T.P. Mullaney, R.K. Maes, 2004. Experimental inoculation of pregnant swine with type 1 bovine viral diarrhea virus. Journal of Veterinary Medicine, 51: 191-193. doi: 10.1111/j.14390450.2004.00750.x.

Walz, P.H., D.L. Grooms, T. Passler, J.F. Ridpath, R. Tremblay, D.L. Step, R.J. Callan, M.D. Givens, 2010. Control of bovine viral diarrhea virus in ruminants. Journal of Veterinary Internal Medicine, 24: 476-486. doi: 10.1111/j.1939-1676.2010.0502.x.

Weinstock, D., B. Bhudevi, A.E. Castro, 2001. Single-tube sigle-enzyme reverse transcriptase PCR assay for detection of bovine viral diarrhea virus in pooled bovine serum. Journal of Clinical Microbiology, 39(1): 343346. doi: 10.1128/JCM.39.1.343-346.2001.

Wieringa-Jelsma, T., S. Quak, W.L.A. Loeffen, 2006. Limited BVDV transmission and full protection against CSFV transmission in pigs experimentally infected with BVDV type 1b. Veterinary Microbiology, 118: 26-36. doi: 10.1016/j.vetmic.2006.06.014. 